\title{
Occurrence rate of dipolarization fronts in the plasma sheet: Cluster observations
}

\author{
Sudong Xiao ${ }^{1}$, Tielong Zhang ${ }^{2,3}$, Guoqiang Wang ${ }^{2}$, Martin Volwerk ${ }^{3}$, Yasong Ge ${ }^{4}$, Daniel Schmid ${ }^{3}$, Rumi Nakamura ${ }^{3}$, \\ Wolfgang Baumjohann ${ }^{3}$, and Ferdinand Plaschke ${ }^{3}$ \\ ${ }^{1}$ CAS Key Laboratory of Geospace Environment, University of Science and Technology of China, Hefei, China \\ ${ }^{2}$ Harbin Institute of Technology, Shenzhen, China \\ ${ }^{3}$ Space Research Institute, Austrian Academy of Sciences, Graz, Austria \\ ${ }^{4}$ Institute of Geology and Geophysics, Chinese Academy of Sciences, Beijing, China \\ Correspondence to: Tielong Zhang (tielong.zhang@oeaw.ac.at)
}

Received: 5 February 2017 - Revised: 24 July 2017 - Accepted: 26 July 2017 - Published: 29 August 2017

\begin{abstract}
We investigate the occurrence rate of dipolarization fronts (DFs) in the plasma sheet by taking full advantage of all four Cluster satellites (C1-4) from years 2001 to 2009. In total, we select 466 joint-observation DF events, in which $318,282,254$, and 236 DFs are observed by $\mathrm{C} 1, \mathrm{C} 2, \mathrm{C} 3$, and $\mathrm{C} 4$, respectively. Our findings are as follows: (1) the maximum occurrence rate is $\sim 15.3$ events per day at $X \sim 15 R_{\mathrm{E}}$ in the $X Y$ plane, and the average occurrence rate is $\sim 5.4$ events per day over the whole observation period; (2) the occurrence rate on the dusk side of the plasma sheet is larger and decreases with increasing $B_{X Y} / B_{\text {Lobe }}$; (3) the occurrence rate within $|Y|<6 R_{\mathrm{E}}$ increases gradually from $X \approx-19$ to $-15 R_{\mathrm{E}}$ and then decreases from $X \approx-15$ to $-10 R_{\mathrm{E}}$; (4) the occurrence rate when $\mathrm{AE}>200 \mathrm{nT}$ is much larger than that when $\mathrm{AE}<200 \mathrm{nT}$, indicating that DFs preferentially occur during high geomagnetic activity. The magnetic pileup and earthward and duskward ion flows could contribute to the increases in the occurrence rate from $X \approx-19$ to $-15 R_{\mathrm{E}}$. We suggest that both geomagnetic activity and multiple DFs contribute to the high occurrence rate of the DFs. In addition, the finite length of the DF in the dawn-dusk direction can affect the chance that a satellite observes the DF.
\end{abstract}

Keywords. Magnetospheric physics (plasma sheet)

\section{Introduction}

Dipolarization fronts (DFs) in the magnetotail plasma sheet have been widely studied in the last decade (Ge et al., 2008, 2012; Volwerk et al., 2008; Schmid et al., 2011, 2015, 2016; Runov et al., 2011; Fu et al., 2012a, 2013; Liu et al., 2013a, b; Lu et al., 2013; Huang et al., 2015; Pritchett et al., 2014; Wang et al., 2016). DFs are regarded as tangential discontinuities (Schmid et al., 2011; Fu et al., 2012a, b) usually separating the ambient dense plasma from the low-density plasma in the fast flow (Runov et al., 2011). However, in around $25 \%$ of cases, the density in the fast flow is higher than in the ambient plasma (Schmid et al., 2015). DFs are characterized by a sharp and large-amplitude increase in the $Z_{\mathrm{GSM}}$ component of the magnetic field (Nakamura et al., 2002; Ohtani et al., 2004). The potential mechanisms generating DFs are transient reconnection (Sitnov et al., 2009; Fu et al., 2013) and interchange instability (Lu et al., 2013; Pritchett et al., 2014).

DFs play a significant role in the magnetospheric dynamics (Zhou et al., 2010; Fu et al., 2011, 2012c, 2014; Ge et al., 2012; Hwang et al., 2014; Wang et al., 2016). The energetic ion anisotropies in the near-Earth plasma sheet show no strong correlation with Auroral Electrojet (AE) index, indicating that its acceleration sources are localized (Luo et al., 2014). DFs can locally accelerate ions and electrons (Zhou et al., 2010; Fu et al., 2011). Wave-particle interactions, instabilities, and increased energy of plasma particles could occur during a DF (Hwang et al., 2014; Wang et al., 2016; Grigorenko et al., 2017). DFs are found to have a close relation with fast flows in the plasma sheet and substorms (Nakamura et al., 2002; Takada et al., 2006; Volwerk et al., 2008; Schmid 


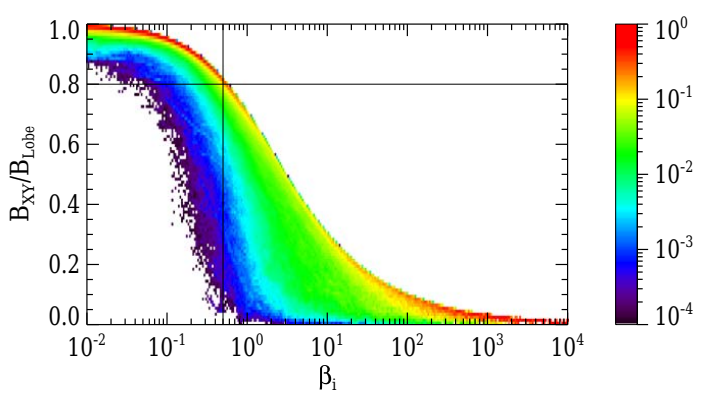

Figure 1. Data distribution at different $\beta_{\mathrm{i}}$ values along a distance relative to the neutral sheet obtained from $\mathrm{C} 1$ in the regions $X<-10 R_{\mathrm{E}}$ and $|Y|<12 R_{\mathrm{E}}$. The steps along the $x$ axis are $\log _{10}\left(\beta_{\mathrm{i}}\right)=0.02$ and along the $y$ axis are $B_{X Y} / B_{\text {Lobe }}=0.01$. The value in each bin is determined by the number of data points in that bin divided by the total data number in the corresponding column along the $y$ axis.

et al., 2011; Ge et al., 2012). The typical length scales of fast flows are $2-3 R_{\mathrm{E}}$ in the dawn-dusk direction and $1.5-2 R_{\mathrm{E}}$ in the north-south direction (Nakamura et al., 2004). Liu et al. (2013b) statistically found that the length scale of DFs in the dawn-dusk direction is about $3 R_{\mathrm{E}}$.

Occurrence rate of the DF in the plasma sheet could help to judge the importance of the DF in the magnetospheric dynamics. Based on Cluster 1 data, Fu et al. (2012a) studied the occurrence rate of the earthward-propagating DFs in the regions $-20<X_{\mathrm{GSM}}<-10 R_{\mathrm{E}},\left|Y_{\mathrm{GSM}}\right|<12 R_{\mathrm{E}}$, and $\left|Z_{\mathrm{GSM}}\right|<5 R_{\mathrm{E}}$. They found that the occurrence rate increases gradually from $r=20$ to $15 R_{\mathrm{E}}$ and then decreases rapidly from $r=15$ to $10 R_{\mathrm{E}}$, in which $r$ is the distance to the center of the Earth in the $X Y_{\mathrm{GSM}}$ plane. The authors suggested that this may be associated with the increasing pileup of the magnetic flux from $r=20$ to $15 R_{\mathrm{E}}$ and the strong ambient magnetic field at $r<13 R_{\mathrm{E}}$ because it becomes difficult to distinguish a DF from the strong ambient magnetic field. The maximum occurrence rate of the DFs occurs at $Z_{\mathrm{GSM}} \sim 0$ and $r \sim 15 R_{\mathrm{E}}$ with 6.2 events per day. The criteria $\max \left(\beta_{\mathrm{i}}\right)>0.5$ used by Fu et al. (2012a) means that the selected DFs are in the plasma sheet, where $\beta_{\mathrm{i}}$ is the ratio of the ion thermal pressure and the magnetic pressure. We note that some data in the regions $-10>X_{\mathrm{GSM}}>-20 R_{\mathrm{E}},-12<Y_{\mathrm{GSM}}<12 R_{\mathrm{E}}$, and $-5<Z_{\mathrm{GSM}}<5 R_{\mathrm{E}}$ could be in the plasma sheet boundary layer or lobe, which can make the occurrence rate of the DF in the plasma sheet underestimated.

The primary aim of this study is to get a reliable occurrence rate of the DF in the plasma sheet. DFs have a finite length in the dawn-dusk direction; thus, one satellite could miss the observation of a DF. In this study, we use all four Cluster satellites (C1-4) to further study the occurrence rate of the DF in the plasma sheet. We also discuss the contribution of geomagnetic activity and fast flows to the occurrence rate of the DFs.
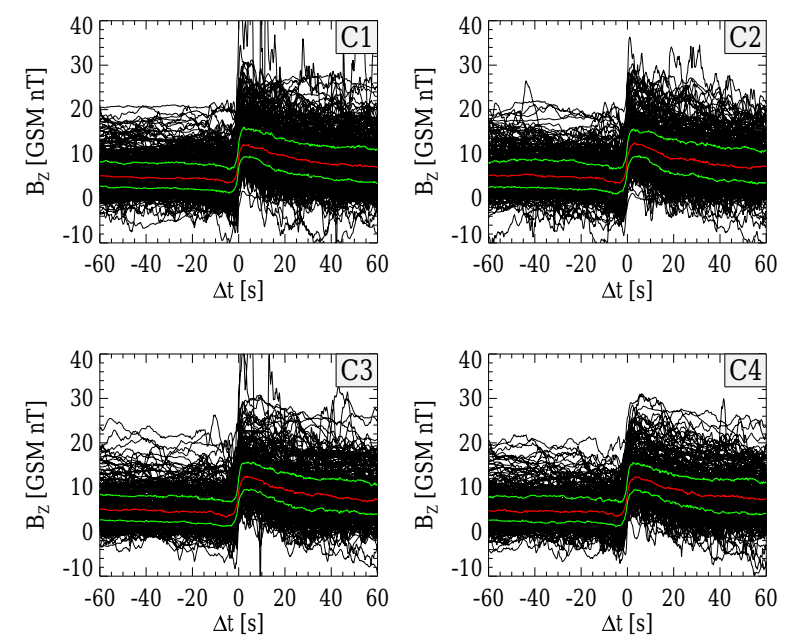

Figure 2. Superposed epoch analysis of 318, 282, 254, and 236 DFs that are selected by $\mathrm{C} 1, \mathrm{C} 2, \mathrm{C} 3$, and $\mathrm{C} 4$, respectively. The profiles of each DF event are centered at $t_{\mathrm{DF}}$. The red and upper and lower green lines indicate the medians, upper quartiles, and lower quartiles of the data, respectively.

\section{Selection of DFs}

Cluster, which has an apogee of $\sim 19.6 R_{\mathrm{E}}$ and a perigee of $\sim 4 R_{\mathrm{E}}$ with a polar orbit, consists of four identical satellites (Escoubet et al., 2001). These satellites constitute a tetrahedron configuration with inter-spacecraft distances varying from 100 to $18000 \mathrm{~km}$. We use the magnetic field data with $5 \mathrm{~Hz}$ resolution obtained by the fluxgate magnetometer (Balogh et al., 2001) from all four Cluster satellites and the $4 \mathrm{~s}$ ion data obtained by the hot ion analyzer (HIA) of the Cluster Ion Spectrometer (CIS) experiment (Rème et al., 2001) from C1 during Cluster tail seasons from 2001 to 2009.

The plasma sheet configuration is greatly affected by the magnetic dipole tilt angle and solar wind conditions (e.g., Schmid et al., 2011; Vörös et al., 2014; Xiao et al., 2016). Therefore, we use $B_{X Y} / B_{\text {Lobe }}$ as a proxy of the distance of a satellite from the neutral sheet, in which $B_{X Y}=\sqrt{B_{X}^{2}+B_{Y}^{2}}$ in GSM (this coordinate system is used throughout the paper unless otherwise specified). The lobe magnetic field is calculated from

$B_{\text {Lobe }}=\sqrt{2 \mu_{0}\left(P_{\mathrm{i}}+P_{B}\right)}$

based on the assumption that the total pressure in the plasma sheet is balanced by the magnetic pressure in the tail lobe, in which $P_{\mathrm{i}}$ is the ion thermal pressure and $P_{B}$ is the local magnetic pressure. C2-4 have no or not enough ion data. Therefore, we use $B_{\text {Lobe }}$ from $\mathrm{C} 1$ and $B_{X Y}$ from C2-4 to estimate the distance of $\mathrm{C} 2-4$ from the neutral sheet. To make such a $B_{\text {Lobe }}$ reliable, we require that the distance between $\mathrm{C} 1$ and C2-4 in the $X$ direction is less than $1 R_{\mathrm{E}}$, and we find that $\sim 92 \%$ of these remaining distances between $\mathrm{C} 1$ and $C 2-4$ in the $Z$ direction are less than $0.5 R_{\mathrm{E}}$. Figure 1 shows data dis- 
(a) $15-08-2001$

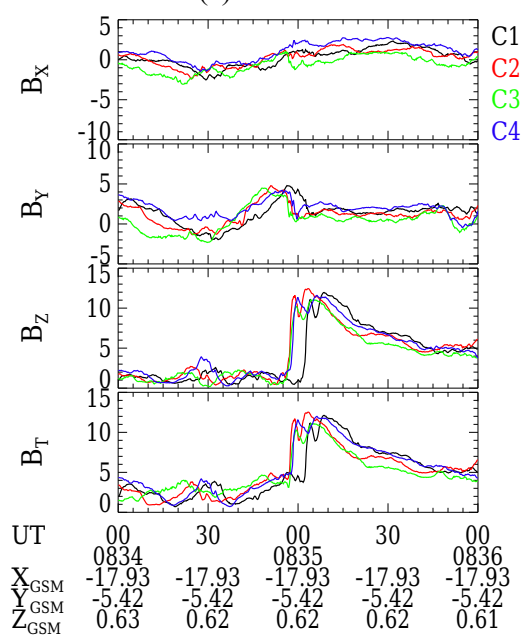

(b) 09-09-2007

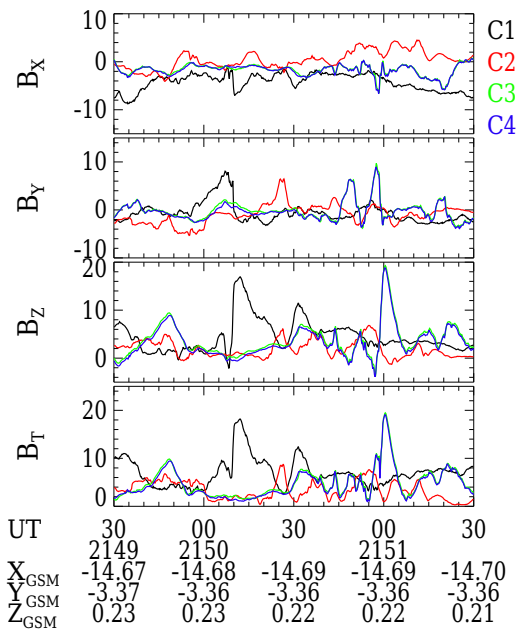

Figure 3. The magnetic field data of two DF events on 15 August 2001 (a) and 9 September 2007 (b). Black, red, green, and blue colors indicate data from $\mathrm{C} 1, \mathrm{C} 2, \mathrm{C} 3$, and $\mathrm{C} 4$, respectively.

tribution in $\beta_{\mathrm{i}}-B_{X Y} / B_{\text {Lobe }}$ space. One can find that the data with $B_{X Y} / B_{\text {Lobe }}<0.8$ contain most of the data with $\beta_{\mathrm{i}}>0.5$ except for a small number of data with $\beta_{\mathrm{i}}<0.5$. Therefore, we use $\left|B_{X Y} / B_{\text {Lobe }}\right|<0.8$ to replace $\beta_{\mathrm{i}}>0.5$ as the criterion of the plasma sheet.

We use a $3 \mathrm{~min}$ window to detect DF events at $-19<X<-10 R_{\mathrm{E}}$ and $|Y|<12 R_{\mathrm{E}}$ with a step of $1.5 \mathrm{~min}$ based on the following criteria: (1) in each window, the satellite is located in the plasma sheet, i.e., $\left|B_{X Y} / B_{\text {Lobe }}\right|<0.8$. (2) The maximum inclination angle of the magnetic field $\left(\theta=\arctan \left(\frac{B_{Z}}{\sqrt{B_{X}^{2}+B_{Y}^{2}}}\right)\right)$ is larger than $45^{\circ}$, and the difference in elevation angle between maximum $B_{Z}\left(B_{Z_{-} \_\max }\right)$ and minimum $B_{Z}\left(B_{Z_{-} \text {min }}\right)$ exceeds $10^{\circ}$. (3) The time of the "potential DF" $t_{\mathrm{DF}}$ is defined as the time between $B_{Z_{-} \max }$ and $B_{Z_{-} \min }$, and the corresponding $B_{Z}$ is equal to $\left(B_{Z_{-} \min }+\right.$ $\left.B_{Z_{-} \text {max }}\right) / 2$. We require that the value of the maximum $B_{Z}$ minus the minimum $B_{Z}$ between $t_{\mathrm{DF}}-3 \mathrm{~s}$ and $t_{\mathrm{DF}}+3 \mathrm{~s}$ exceeds $4 \mathrm{nT}$. Then we visually inspect all the events selected based on the criteria above to exclude events that are not typical DFs based on profiles of the magnetic field data. Consequently, 318, 282, 254, and 236 DFs have been selected by $\mathrm{C} 1, \mathrm{C} 2, \mathrm{C} 3$, and $\mathrm{C} 4$, respectively.

Figure 2 presents the superposed epoch analysis of the DF events observed by $\mathrm{C} 1, \mathrm{C} 2, \mathrm{C} 3$, and $\mathrm{C} 4$ during the intervals $1 \mathrm{~min}$ before and after $t_{\mathrm{DF}}$. The red and upper and lower green lines in Fig. 2 indicate the medians, upper quartiles, and lower quartiles, respectively. The profiles of the red lines in all four rows in each panel are in agreement with the typical DF (Ohtani et al., 2004; Schmid et al., 2011; Fu et al., 2012a). Only 15 out of 318 DFs observed by $\mathrm{C} 1$ have their maximum velocities less than $150 \mathrm{~km} \mathrm{~s}^{-1}$ in the interval $1.5 \mathrm{~min}$ before and after $t_{\mathrm{DF}}$, which means that the criteria
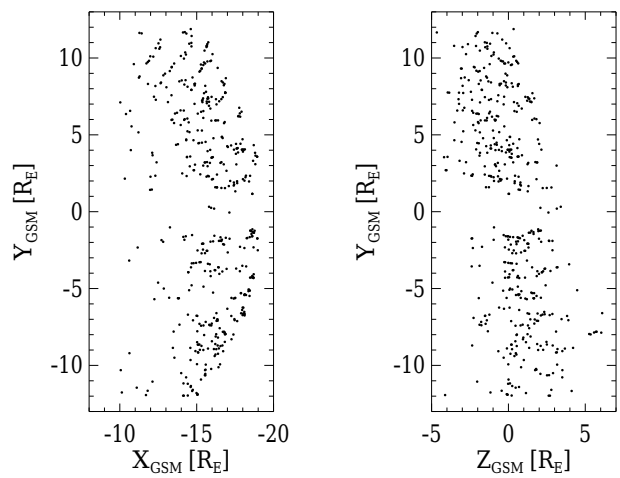

Figure 4. Spatial distribution of $466 \mathrm{DF}$ events in the $X Y$ and $Y Z$ planes.

without ion velocity do not significantly affect the statistical results of the occurrence rate of the DFs in this study.

Considering the typical velocity of DFs (Schmid et al., 2011) and the inter-spacecraft distances of Cluster, we regard any two DF events observed by different satellites as the same joint-observation DF event if their time difference is less than $30 \mathrm{~s}$ before 2005. The distances between the Cluster satellites could be larger than $10000 \mathrm{~km}$ in the $X$ direction since the year 2005 , i.e., a DF could take more than $30 \mathrm{~s}$ to propagate such a distance. Thus, we visually check any two adjacent DFs observed by different satellites with a time difference less than 2 min during this period. If the $B_{Z}$ profiles of both events are similar, we regard them as the same joint-observation DF event. Figure 3 shows two typical jointobservation DF events. For the event on 15 August 2001, the inter-spacecraft distances among the Cluster satellites are $\sim 2000 \mathrm{~km}$, and the time differences of the DFs are less than 10 s. For the event on 9 September 2007, the inter-spacecraft 


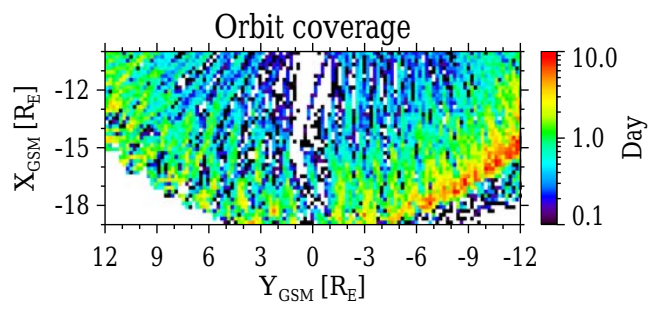

Figure 5. The orbit coverage of all four Cluster satellites in the $X Y$ plane. Bin size is $0.2 R_{\mathrm{E}}$. If at least two satellites are simultaneously in the same bin, we only count the time once for that bin.
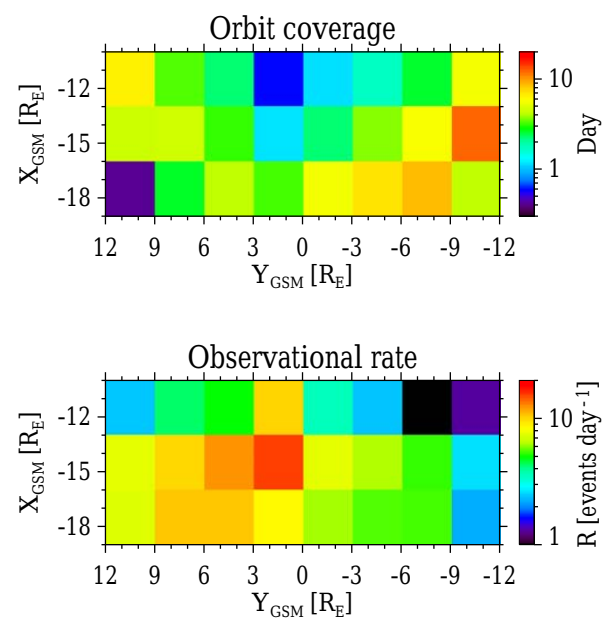

Figure 6. The orbit coverage and the spatial distributions of the occurrence rate of the DFs observed by all four Cluster satellites in the $X Y$ plane. Bin is $3 \times 3 R_{\mathrm{E}}$. If at least two satellites are simultaneously in the same bin, we only count the time once for that bin; if at least two DFs, which belong to a same DF event, are observed by different satellites and located in the same bin, we only count the DF once for that bin.

distances between $\mathrm{C} 1$ and $\mathrm{C} 3-4$ are up to $10000 \mathrm{~km}$, and the time differences of the DFs observed by $\mathrm{C} 1$ and $\mathrm{C} 3-4$ are $\sim 50$ s. In total, 466 joint-observation DF events are selected in present study. We show the spatial distribution of these events in the $X Y$ and $Y Z$ planes in Fig. 4. The distribution in the $Y Z$ plane is in agreement with the distribution of the plasma sheet.

The spatial distribution of the DFs is quite sparse near $Y=$ 0 in Fig. 4. The results of Schmid et al. (2011) and Fu et al. (2012a) also show that there is a gap near $Y=0$ in the spatial distribution of the DFs. We check the orbit coverage of the Cluster satellites in the $X Y$ plane with bin size $0.2 R_{\mathrm{E}}$ as shown in Fig. 5 and find that there are few data near $Y=0$.

\section{Statistical results}

The dawn-dusk scale of DFs is $\sim 3 R_{\mathrm{E}}$ (Liu et al., 2013b), therefore, the spatial bin size in the $X Y$ plane is chosen to be

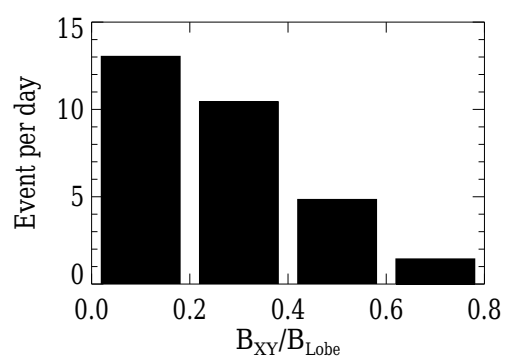

Figure 7. Histogram of the occurrence rate of the DFs along the neutral sheet distance.

$3 R_{\mathrm{E}}$. We use all data with $B_{X Y} / B_{\text {Lobe }}<0.8$ and DF events observed by $\mathrm{C} 1-4$ satellites to determine the occurrence rate of the DFs. If at least two satellites are simultaneously in the same bin, we count the time just once for that bin. In total, there are $\sim 97.3$ days in all bins, and the orbit coverage of the multiple satellites is shown in the upper panel of Fig. 6. If at least $2 \mathrm{DFs}$, which belong to a same joint-observation DF event, are simultaneously in the same bin, we only count one DF event for that bin. Consequently, there is a total of $525 \mathrm{DF}$ events in all bins. The occurrence rate in each bin is determined by the number of the DF events divided by the time Cluster remained in the plasma sheet in that bin. The bottom of Fig. 6 shows the occurrence rate of the DFs in the $X Y$ plane. The maximum occurrence rate is $\sim 15.3$ events per day at $-16<X<-13 R_{\mathrm{E}}$ and $0<Y<3 R_{\mathrm{E}}$, and the average occurrence rate in the entire the $X Y$ plane as shown in Fig. 5 is $\sim 5.4$ events per day. The occurrence rate on the dusk side of the plasma sheet is larger than that on the dawn side. Compared to the dusk side, the occurrence rate on the dawn side is very weak at $-13<X<-10 R_{\mathrm{E}}$. One can also find that the occurrence rate within $|Y|<6$ increases from $X=-19$ to $-15 R_{\mathrm{E}}$ and then decreases from $X=-15$ to $-10 R_{\mathrm{E}}$.

The parameter of $B_{X Y} / B_{\text {Lobe }}$ for each DF event is determined by averaging the value of the magnetic field and $B_{\text {Lobe }}$ between $t_{\mathrm{DF}}-3 \mathrm{~min}$ and $t_{\mathrm{DF}}-2 \mathrm{~min}$ (see also, Liu et al., 2013a). We use all data at $-19<X<-10 R_{\mathrm{E}}$ and $|Y|<12 R_{\mathrm{E}}$ from $\mathrm{C} 1-4$ to determine the occurrence rate of the DFs along the neutral sheet distance, and the results are shown in Fig. 7. The occurrence rates are up to 10 events per day within $B_{X Y} / B_{\text {Lobe }}<0.4$ and are $\sim 1.4$ events per day at $0.6<B_{X Y} / B_{\text {Lobe }}<0.8$.

DFs are associated with plasma flows, especially earthward-moving flows (Schmid et al., 2011; Ge et al., 2012). We select all the ion velocities between $t_{\mathrm{DF}}$ and $t_{\mathrm{DF}}+5 \mathrm{~min}$ for each $\mathrm{DF}$ event from $\mathrm{C} 1$ and present the ion velocity distributions of all the events in Fig. 8. The ion velocities in all distributions are mainly earthward and are faster at $-19<X<-15 R_{\mathrm{E}}$ than at $-15<X<-10 R_{\mathrm{E}}$, which is in agreement with the braking of the plasma flows in the near-Earth plasma sheet (Shiokawa et al., 1997). For $V_{X Y}>200 \mathrm{~km} \mathrm{~s}^{-1}$, velocities in all the panels in Fig. 8 

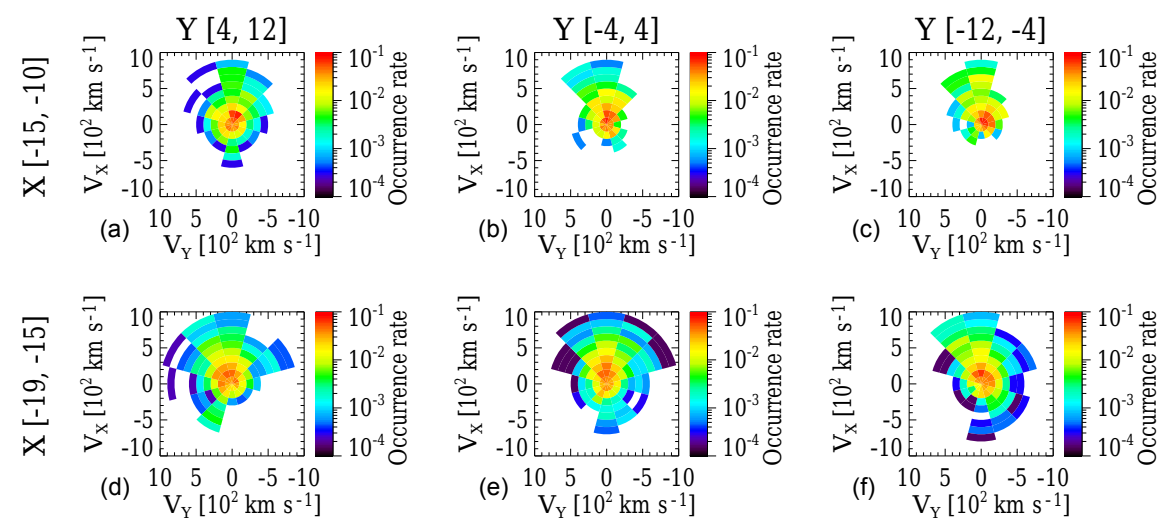

Figure 8. The ion velocity distributions of the DF events from $\mathrm{C} 1$ in different regions. The value in each bin is determined by the data number of this bin divided by the total data number in that region. The ion velocities for each DF are selected in the interval between $t_{\mathrm{DF}}$ and $t_{\mathrm{DF}}+5 \mathrm{~min}$.

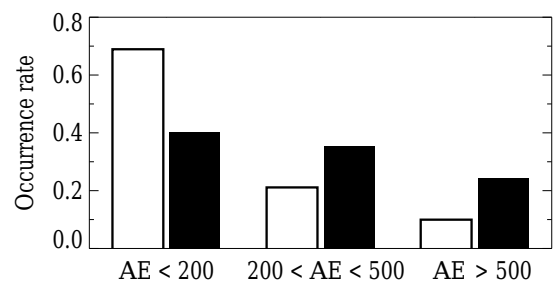

Figure 9. Histograms of the percentage of time that multiple satellites are in the plasma sheet (left bar) and DF events (right bar) when $\mathrm{AE}<200 \mathrm{nT}, 200<\mathrm{AE}<500 \mathrm{nT}$, and $\mathrm{AE}>500 \mathrm{nT}$; if at least two satellites are simultaneously in the plasma sheet, we count the time just once.

show dawn-dusk asymmetry and tend to be somewhat duskward except for panel (a). The velocity distributions at $-15<X<-10 R_{\mathrm{E}}$ and $-12<Y<-4 R_{\mathrm{E}}$ show that the ion velocities in this region are generally small compared to other regions in Fig. 8. The ion velocities show duskward asymmetry, which is in agreement with previous findings (Juusola et al., 2011; Liu et al., 2014). The ion gradient drift could contribute to such asymmetry when close to the inner edge of the plasma sheet (Hori et al., 2000).

Next, we check how many joint-observation DF events occur at high geomagnetic activity. As shown in Fig. 9, the percentage of the time when the Cluster satellites located in the plasma sheet are about 68.9, 21.1, and 10\% (white bars), and the percentage of the joint-observation DF events are about 40.3, 35.4, and $24.3 \%$ (black bars) under $\mathrm{AE}<200$ $\mathrm{nT}, 200<\mathrm{AE}<500 \mathrm{nT}$, and $\mathrm{AE}>500 \mathrm{nT}$, respectively.

Multiple DFs can occur during a short period, which could be one reason for the high occurrence rate of the DFs. We calculate the time difference of any two adjacent jointobservation DF events and show the histogram of the time differences in Fig. 10. We find that the time differences of 80,118 , and 151 adjacent joint-observation DF events are within 5,10 , and $15 \mathrm{~min}$, respectively.

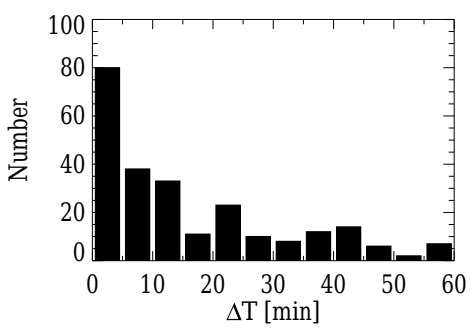

Figure 10. Histograms of the number of the adjacent events versus the time difference between two adjacent DFs for a certain adjacent event. Any two adjacent DFs are regarded as one adjacent event.

\section{Discussion}

Our results show that the occurrence rate of the DFs is larger on the dusk side of the plasma sheet than on the dawn side and the maximum occurrence rate occurs in the central plasma sheet, which is in agreement with the findings of Fu et al. (2012a) and Liu et al. (2013b). The maximum occurrence rate is 15.3 events per day in the $X Y$ plane, much higher than that of Fu et al. (2012a), who reported values of 6.2 per day. The maximum occurrence rate of the DFs in our study is near $X=-15 R_{\mathrm{E}}$, and the occurrence rate decreases rapidly toward the Earth. Fu et al. (2012a) provided an explanation of the occurrence rate of DFs decreasing from $X=-15$ to $-10 R_{\mathrm{E}}$ that compared to the strong background magnetic field in the near-Earth region. The increase of $B_{Z}$ at the DF is not prominent, resulting in many events excluded by the criteria $\max \left(B_{Z}\right)-\min \left(B_{Z}\right)>4 \mathrm{nT}$ and the difference in elevation angle $>10^{\circ}$. Ion flows are found to be braked from $X=-15$ to $-10 R_{\mathrm{E}}$ (Shiokawa et al., 1997). Therefore, we suggest that the braking of ion flows could be another reason that the occurrence rate of the DFs decreases rapidly from $X=-15$ to $-10 R_{\mathrm{E}}$. Schmid et al. (2016) provided a comparative study of DFs observed by the Magnetospheric Multiscale (MMS) mission and Cluster at radial distances below 
12 and $20 R_{\mathrm{E}}$, respectively. They found that $\sim 57 \%$ of the DFs observed by MMS propagate faster than $150 \mathrm{~km} \mathrm{~s}^{-1}$, while for Cluster, the percentage is only $\sim 35 \%$. Their findings contradict the idea that the velocity of DFs becomes slower when DFs propagate earthward. Schmid et al. (2016) explained that this contradiction might be because MMS and Cluster observed the DFs in different conditions, such as tail season, solar cycle, and so on.

Figure 6 shows that the occurrence rate within $|Y|<6 R_{\mathrm{E}}$ gradually increases from $X=-19$ to $-15 R_{\mathrm{E}}$, which is in agreement with the findings of $\mathrm{Fu}$ et al. (2012a). Fu et al. (2012a) suggested that this may be associated with the increasing pileup of the magnetic flux from $X=-20$ to $-15 R_{\mathrm{E}}$. We find that the fast flows are mainly earthward and somewhat duskward in the interval between $t_{\mathrm{DF}}$ and $t_{\mathrm{DF}}+5 \mathrm{~min}$, as shown in Fig. 8. DFs are the front of fast flows in the plasma sheet (see Schmid et al., 2011). Schmid et al. (2015) reported that DFs can be classified into two categories, and their observations suggested that the plasma flow direction of one category is along the magnetic tension force direction, while for another category the plasma flow is slightly tilted toward the dusk side. The occurrence rate of the DFs in Fig. 6 tends to be stronger on the dusk side than that on the dawn side. Therefore, we infer that the earthward and duskward fast flows could affect the asymmetry of the occurrence rate of the DFs.

Observations show that the typical scale of DFs in the dawn-dusk direction is $\sim 3 R_{\mathrm{E}}$ (Liu et al., 2013b; Huang et al., 2015). We assume that the DF propagates only in the $X$ direction and the scale of the DF in the dawn-dusk direction is $3 R_{\mathrm{E}}$; thus, a satellite located at $Y=0$ could observe the DF with the central line located between $Y=-1.5$ and $1.5 R_{\mathrm{E}}$. Therefore, the finite length of the DF in the dawndusk direction can affect the change that a satellite observes during a DF event at a certain position. It could be one of the reasons that the maximum occurrence rate of the DFs is up to 15.3 events per day. Another reason is that multiple DFs generated by multiple burst bulk flows can occur in the plasma sheet (Hwang et al., 2011). Figure 10 shows that $\sim 33.2 \%$ of DF events happen after previous DFs within $15 \mathrm{~min}$.

The DF is a common feature of substorm dynamics in the plasma sheet (Ge et al., 2011, 2012). Only $\sim 31.1 \%$ of the Cluster data are during $\mathrm{AE}>200 \mathrm{nT}$, while we find that $\sim 59.7 \%$ of the DFs in our study are observed under such AE conditions. Therefore, the occurrence rate of the DFs tends to be larger when the geomagnetic activity is higher. DFs are the leading edge of the dipolaring flux bundle (DFB) (Liu et al., 2013a, 2014). The characteristics of the DFs in this study just account for partial DFBs since the DFs we select require the criteria that $B_{Z}$ increases $4 \mathrm{nT}$ within $6 \mathrm{~s}$. Despite this, it has also been found that the occurrence rate of DFB increases when geomagnetic activities are higher (Liu et al., 2014). The average occurrence rate of the DFs is 5.4 events per day, close to the occurrence rate of substorms, which is $\sim 8.7$ events per day (see Borovsky et al., 1993).

\section{Summary}

In this paper, we study the occurrence rate of the DFs in the plasma sheet by using all four Cluster satellites from the years 2001 to 2009 . In total, we select 466 jointobservation DF events based on our criteria, and C1, C2, C3, and C4 observe 318, 282, 254, and 236 DFs, respectively. The maximum occurrence rate of the DFs in the $X Y$ plane is $\sim 15.3$ events per day at $-16<X<-13 R_{\mathrm{E}}$ and $0<Y<3 R_{\mathrm{E}}$, and the average occurrence rate is $\sim 5.4$ events per day, in which the bin size is $3 R_{\mathrm{E}}$. The occurrence rate decreases with increasing $B_{X Y} / B_{\text {Lobe }}$, indicating that the maximum occurrence rate is in the central plasma sheet. The occurrence rate is larger on the dusk side of the plasma sheet than that on the dawn side.

The occurrence rate of the DFs within $|Y|<6 R_{\mathrm{E}}$ increases gradually from $X=-19$ to $-15 R_{\mathrm{E}}$ and then decreases rapidly from $X=-15$ to $-10 R_{\mathrm{E}}$. We suggest that both the magnetic pileup and the earthward and duskward ion flows contribute to the increase in occurrence rate from $X=-19$ to $-15 R_{\mathrm{E}}$, while the decrease in occurrence rate from $X=-15$ to $-10 R_{\mathrm{E}}$ could be associated with the braking of ion flows. The occurrence rate of the DFs at $\mathrm{AE}>200 \mathrm{nT}$ is much larger than that at $\mathrm{AE}<200 \mathrm{nT}$, indicating that $\mathrm{DFs}$ prefer to occur at high geomagnetic activity. Multiple DF events can occur in a short period, which is one reason for the large occurrence rate of the DFs. In addition, the length of the DF in the dawn-dusk direction could affect the probability that a satellite observes a DF at a certain place in this direction.

Data availability. All Cluster data used in this study can be retrieved from the Cluster Science Archive (http://www.cosmos.esa. int/web/csa), and AE index data used in this work are obtained from the Space Physics Data Facility OMNIWeb interface (http: //omniweb.gsfc.nasa.gov).

Competing interests. The authors declare that they have no conflict of interest.

Acknowledgements. This work in China is supported by the NSFC grant 41574173. This work in Austria is supported by EU FP7 grant 263325 - ECLAT, Austrian Science Fund FWF P23862-N16 and fund P24740-N27. We are grateful to the Cluster Science Archive for providing Cluster data and the Space Physics Data Facility for providing AE index data.

The topical editor, Elias Roussos, thanks the two anonymous referees for help in evaluating this paper. 


\section{References}

Balogh, A., Carr, C. M., Acuña, M. H., Dunlop, M. W., Beek, T. J., Brown, P., Fornacon, K.-H., Georgescu, E., Glassmeier, K.H., Harris, J., Musmann, G., Oddy, T., and Schwingenschuh, K.: The Cluster Magnetic Field Investigation: overview of in-flight performance and initial results, Ann. Geophys., 19, 1207-1217, https://doi.org/10.5194/angeo-19-1207-2001, 2001.

Borovsky, J. E., Nemzek, R. J., and Belian, R. D.: The occurrence rate of magnetospheric-substorm onsets: Random and periodic substorms, J. Geophys. Res., 98, 3807-3813, https://doi.org/10.1029/92JA02556, 1993.

Escoubet, C. P., Fehringer, M., and Goldstein, M.: Introduction The Cluster mission, Ann. Geophys., 19, 1197-1200, https://doi.org/10.5194/angeo-19-1197-2001, 2001.

Fu, H. S., Khotyaintsev, Y. V., André, M., and Vaivads, A.: Fermi and betatron acceleration of suprathermal electrons behind dipolarization fronts, Geophys. Res. Lett., 38, L16104, https://doi.org/10.1029/2011GL048528, 2011.

Fu, H. S., Khotyaintsev, Y. V., Vaivads, A., André, M., and Huang, S. Y.: Occurrence rate of earthward-propagating dipolarization fronts, Geophys. Res. Lett., 39, L10101, https://doi.org/10.1029/2012GL051784, 2012a.

Fu, H. S., Khotyaintsev, Y. V., Vaivads, A., Andre, M., and Huang, S. Y.: Electric structure of dipolarization front at sub-proton scale, Geophys. Res. Lett., 39, L06105, https://doi.org/10.1029/2012GL051274, 2012b.

Fu, H. S., Khotyaintsev, Y. V., Vaivads, A., André, M., Sergeev, V. A., Huang, S. Y., Kronberg, E. A., and Daly, P. W.: Pitch angle distribution of suprathermal electrons behind dipolarization fronts: A statistical overview, J. Geophys. Res., 117, A12221, https://doi.org/10.1029/2012JA018141, 2012c.

Fu, H. S., Cao, J. B., Khotyaintsev, Yu. V., Sitnov, M. I., Runov, A., Fu, S. Y., Hamrin, M., André, M., Retinò, A., Ma, Y. D., Lu, H. Y., Wei, X. H., and Huang, S. Y.: Dipolarization fronts as a consequence of transient reconnection: In situ evidence, Geophys. Res. Lett., 40, 6023-6027, https://doi.org/10.1002/2013GL058620, 2013

Fu, H. S., Cao, J. B., Cully, C. M., Khotyaintsev, Y. V., Vaivads, A., Angelopoulos, V., Zong, Q.-G., Santolík, O., Macúšová, E., André, M., Liu, W. L., Lu, H. Y., Zhou, M., Huang, S. Y., and Zhima, Z.: Whistler-mode waves inside flux pileup region: Structured or unstructured?, J. Geophys. Res., 119, 9089-9100, https://doi.org/10.1002/2014JA020204, 2014.

Ge, Y. S., Russell, C. T., and Hsu, T.-S.: Implication of multiple depolarization event near $9 \mathrm{RE}$ for the physics of substorms, Adv. Space Res., 41, 1243-1251, https://doi.org/10.1016/j.asr.2007.12.010, 2008.

Ge, Y. S., Raeder, J., Angelopoulos, V., Gilson, M. L., and Runov, A.: Interaction of dipolarization fronts within multiple bursty bulk flows in global MHD simulations of a substorm on 27 February 2009, J. Geophys. Res., 116, A00I23, https://doi.org/10.1029/2010JA015758, 2011.

Ge, Y. S., Zhou, X.-Z., Liang, J., Raeder, J., Raeder, M. L., Donovan, E., Angelopoulos, V., and Runov, A.: Dipolarization fronts and associated auroral activities: 1. Conjugate observations and perspectives from global MHD simulations, J. Geophys. Res., 117, A10226, https://doi.org/10.1029/2012JA017676, 2012.

Grigorenko, E. E., Kronberg, E. A., and Daly, P. W.: Heating and acceleration of charged particles dur- ing magnetic dipolarizations, Cosmic Res., 55, 57-66, https://doi.org/10.1134/S0010952517010063, 2017.

Hori, T., Maezawa, K., Saito, Y., and Mukai, T.: Average profile of ion flow and convection electric field in the near Earth plasma sheet, Geophys. Res. Lett., 27, 1623-1626, https://doi.org/10.1029/1999GL003737, 2000.

Huang, S. Y., Fu, H. S., Vaivads, A., Yuan, Z. G., Pang, Y., Zhou, M., Khotyaintsev, Yuri V., Deng, X. H., André, M., Zhang, L., Fu, S., Li, H. M., and Wang, D. D.: Dawn-dusk scale of dipolarization front in the earth's magnetotail: multi-cases study, Astrophys. Space Sci., 357, 1-7, https://doi.org/10.1007/s10509-0152298-3, 2015.

Hwang, K.-J., Goldstein, M. L., Vinas, A. F., Schriver, D., and Ashour-Abdalla, M.: Wave-particle interactions during a dipolarization front event, J. Geophys. Res.-Space, 119, 2484-2493, https://doi.org/10.1002/2013JA019259, 2014.

Hwang, K.-J., Goldstein, M. L., Lee, E., and Pickett, J. S.: Cluster observations of multiple dipolarization fronts, J. Geophys. Res., 116, A00I32, https://doi.org/10.1029/2010JA015742, 2011.

Juusola, L., Østgaard, N., and Tanskanen, E.: Statistics of plasma sheet convection, J. Geophys. Res., 116, A08201, https://doi.org/10.1029/2011JA016479, 2011.

Liu, J., Angelopoulos, V., Runov, A., and Zhou, X.-Z.: On the current sheets surrounding dipolarizing flux bundles in the magnetotail: The case for wedgelets, J. Geophys. Res.-Space, 118, 20002020, https://doi.org/10.1002/jgra.50092, 2013a.

Liu, J., Angelopoulos, V., Zhou, X.-Z., Runov, A., and Yao, Z. H.: On the role of pressure and flow perturbations around dipolarizing flux bundles, J. Geophys. Res.-Space, 118, 7104-7118, https://doi.org/10.1002/2013JA019256, 2013b.

Liu, J., Angelopoulos, V., Zhou, X.-Z., and Runov, A.: Magnetic flux transport by dipolarizing flux bundles, J. Geophys. Res.Space, 119, 909-926, https://doi.org/10.1002/2013JA019395, 2014.

Lu, H. Y., Cao, J. B., Zhou, M., Fu, H. S., Nakamura, R., Zhang, T. L., Khotyaintsev, Y. V., Ma, Y. D., and Tao, D.: Electric structure of dipolarization fronts associated with interchange instability in the magnetotail, J. Geophys. Res.-Space, 118, 6019-6025, https://doi.org/10.1002/jgra.50571, 2013.

Luo, H., Kronberg, E. A., Grigorenko, E. E., Fränz, M., Daly, P. W., Chen, G. X., Du, A. M., Kistler, L. M., and Wei, Y.: Evidence of strong energetic ion acceleration in the near-Earth magnetotail, Geophys. Res. Lett., 41, 3724-3730, https://doi.org/10.1002/2014GL060252, 2014.

Nakamura, R., Baumjohann, W., Klecker, B., Bogdanova, Y., Balogh, A., Rème, H., Bosqued, J. M., Dandouras, I., Sauvaud, J. A., Glassmeier, K.-H., Kistler, L., Mouikis, C., Zhang, T. L., Eichelberger, H., and Runov, A.: Motion of the dipolarization front during a flow burst event observed by Cluster, Geophys. Res. Lett., 29, 1942, https://doi.org/10.1029/2002GL015763, 2002.

Nakamura, R., Baumjohann, W., Mouikis, C., Kistler, L. M., Runov, A., Volwerk, M., Asano, Y., Vörös, Z., Zhang, T. L., Klecker, B., Rème, H., and Balogh, A.: Spatial scale of high-speed flows in the plasma sheet observed by Cluster, Geophys. Res. Lett., 31, L09804, https://doi.org/10.1029/2004GL019558, 2004.

Ohtani, S., Shay, M. A., and Mukai, T.: Temporal structure of the fast convective flow in the plasma sheet: Comparison between 
observations and two-fluid simulations, J. Geophys. Res., 109, A03210, https://doi.org/10.1029/2003JA010002, 2004.

Pritchett, P. L., Coroniti, F. V., and Nishimura, Y.: The kinetic ballooning/interchange instability as a source of dipolarization fronts and auroral streamers, J. Geophys. Res.-Space, 119, 47234739, https://doi.org/10.1002/2014JA019890, 2014.

Rème, H., Aoustin, C., Bosqued, J. M., Dandouras, I., Lavraud, B., Sauvaud, J. A., Barthe, A., Bouyssou, J., Camus, Th., Coeur-Joly, O., Cros, A., Cuvilo, J., Ducay, F., Garbarowitz, Y., Medale, J. L., Penou, E., Perrier, H., Romefort, D., Rouzaud, J., Vallat, C., Alcaydé, D., Jacquey, C., Mazelle, C., d'Uston, C., Möbius, E., Kistler, L. M., Crocker, K., Granoff, M., Mouikis, C., Popecki, M., Vosbury, M., Klecker, B., Hovestadt, D., Kucharek, H., Kuenneth, E., Paschmann, G., Scholer, M., Sckopke, N., Seidenschwang, E., Carlson, C. W., Curtis, D. W., Ingraham, C., Lin, R. P., McFadden, J. P., Parks, G. K., Phan, T., Formisano, V., Amata, E., Bavassano-Cattaneo, M. B., Baldetti, P., Bruno, R., Chionchio, G., Di Lellis, A., Marcucci, M. F., Pallocchia, G., Korth, A., Daly, P. W., Graeve, B., Rosenbauer, H., Vasyliunas, V., McCarthy, M., Wilber, M., Eliasson, L., Lundin, R., Olsen, S., Shelley, E. G., Fuselier, S., Ghielmetti, A. G., Lennartsson, W., Escoubet, C. P., Balsiger, H., Friedel, R., Cao, J.-B., Kovrazhkin, R. A., Papamastorakis, I., Pellat, R., Scudder, J., and Sonnerup, B.: First multispacecraft ion measurements in and near the Earth's magnetosphere with the identical Cluster ion spectrometry (CIS) experiment, Ann. Geophys., 19, 1303-1354, https://doi.org/10.5194/angeo-19-1303-2001, 2001.

Runov, A., Angelopoulos, V., Zhou, X.-Z., Zhang, X.-J., Li, S., Plaschke, F., and Bonnell, J.: A THEMIS multicase study of dipolarization fronts in the magnetotail plasma sheet, J. Geophys. Res., 116, A05216, https://doi.org/10.1029/2010JA016316, 2011.

Schmid, D., Volwerk, M., Nakamura, R., Baumjohann, W., and Heyn, M.: A statistical and event study of magnetotail dipolarization fronts, Ann. Geophys., 29, 1537-1547, https://doi.org/10.5194/angeo-29-1537-2011, 2011.

Schmid, D., Nakamura, R., Plaschke, F., Volwerk, M., and Baumjohann, W.: Two states of magnetotail dipolarization fronts: A statistical study, J. Geophys. Res.-Space, 120, 1096-1108, https://doi.org/10.1002/2014JA020380, 2015.

Schmid, D., Nakamura, R., Volwerk, M., Plaschke, F., Narita, Y., Baumjohann, W., Magnes, W., Fischer, D., Eichelberger, H. U., Torbert, R. B., Russell, C. T., Strangeway, R. J., Leinweber, H. K., Le, G., Bromund, K. R., Anderson, B. J., Slavin, J. A., and Kepko, E. L.: A comparative study of dipolarization fronts at MMS and Cluster, Geophys. Res. Lett., 43, 6012-6019, https://doi.org/10.1002/2016GL069520, 2016.
Shiokawa, K., Baumjohann, W., and Haerendel, G.: Braking of high-speed flows in the near-Earth tail, Geophys. Res. Lett., 24, 1179-1182, https://doi.org/10.1029/97GL01062, 1997.

Sitnov, M. I., Swisdak, M., and Divin, A. V.: Dipolarization fronts as a signature of transient reconnection in the magnetotail, J. Geophys. Res., 114, A04202, https://doi.org/10.1029/2008JA013980, 2009.

Takada, T., Nakamura, R., Baumjohann, W., Asano, Y., Volwerk, M., Zhang, T. L., Klecker, B., Rème, H., Lucek, E. A., and Carr, C.: Do BBFs contribute to inner magnetosphere dipolarizations: Concurrent Cluster and Double Star observations, Geophys. Res. Lett., 33, L21109, https://doi.org/10.1029/2006GL027440, 2006.

Volwerk, M., Lui, A. T. Y., Lester, M., Walsh, A. P., Alexeev, I., Cao, X., Dunlop, M. W., Fazakerley, A. N., Grocott, A., Kistler, L., Lun, X., Mouikis, C., Pu, Z., Shen, C., Shi, J. K., Taylor, M. G. G. T., Baumjohann, W., Nakamura, R., Runov, A., Vörös, Z., Zhang, T. L., Takada, T., Rème, H., Klecker, B., and Carr, C. M.: Magnetotail dipolarization and associated current systems observed by Cluster and Double Star, J. Geophys. Res., 113, A08S90, https://doi.org/10.1029/2007JA012729, 2008.

Vörös, Z., Facskó, G., Khodachenko, M., Honkonen, I., Janhunen, P., and Palmroth, M.: Windsock memory COnditioned RAM (CO-RAM) pressure effect: Forced reconnection in the Earth's magnetotail, J. Geophys. Res.-Space, 119, 6273-6293, https://doi.org/10.1002/2014JA019857, 2014.

Wang, G. Q., Zhang, T. L., Volwerk, M., Schmid, D., Baumjohann, W., Nakamura, R., and Pan, Z. H.: Mirror mode structures ahead of dipolarization front near the neutral sheet observed by Cluster, Geophys. Res. Lett., 43, 8853-8858, https://doi.org/10.1002/2016GL070382, 2016.

Xiao, S., Zhang, T., Ge, Y., Wang, G., Baumjohann, W., and Nakamura, R.: A statistical study on the shape and position of the magnetotail neutral sheet, Ann. Geophys., 34, 303-311, https://doi.org/10.5194/angeo-34-303-2016, 2016.

Zhou, X.-Z., Angelopoulos, V., Sergeev, V. A., and Runov, A.: Accelerated ions ahead of earthward propagating dipolarization fronts, J. Geophys. Res., 115, A00I03, https://doi.org/10.1029/2010JA015481, 2010. 